Marquette University

e-Publications@Marquette

Economics Faculty Research and Publications

Economics, Department of

4-1-2013

The Impact of Early Commitment on Games

Played: Evidence from College Football Recruiting

Jesse Brickers

Board of Governors of the Federal Reserve System

Andrew Hanson

Marquette University, andrew.r.hanson@marquette.edu

Published version. Southern Economic Journal, Vol. 79, No. 4 (2013): 971-983. DOI. (C) 2013

Southern Economic Association. Used with permission. 


\title{
The Impact of Early Commitment on Games Played: Evidence from College Football Recruiting
}

\author{
Jesse Bricker* and Andrew Hanson†
}

\begin{abstract}
We use data on athletic scholarship acceptance decisions to show that high school football players signal their ability level by delaying commitment. Although colleges can obtain information about student athletes, National Collegiate Athletic Association regulations limit information flow, making private information an important component of the scholarship market. Using ordinary least squares, censored regression, and negative binomial estimation, we show that for a given observed ability level, committing to a scholarship offer early is associated with less playing time after acceptance. In one season and at a typical average early signing date, early-committing athletes played in 0.21 fewer games per season, or about $4 \%$ of the average number of games played.
\end{abstract}

JEL Classification: D82, L83

\section{Introduction}

Information asymmetries are common in social and economic transactions between two parties. Economic agents may have the opportunity to signal positive private information by taking on extra costs, for example, by delaying action (Tracy 1987; Kennan and Wilson 1989; Conlin 1999; Conlin and Emerson 2003) or by taking on higher mental costs (Spence 1973). Typically researchers examine signaling behavior in adult decision makers, some of whom may be highly educated or have experience with bargaining. ${ }^{1}$

We add to this literature by testing for signaling behavior when the economic agent is arguably less sophisticated. Specifically, we test for signaling of private information by high

* Board of Governors of the Federal Reserve System, Division of Research \& Statistics, 20th and C Street NW, MS-153, Washington, DC 20551, USA; E-mail jesse.bricker@frb.gov; corresponding author.

$\dagger$ Department of Economics, Marquette University, P.O. Box 1881, Milwaukee, WI 53201; E-mail andrew.r. hanson@marquette.edu.

The analysis and conclusions set forth are those of the authors and do not represent the views of the Board of Governors or its staff. We would like to thank John Pepper and an extremely helpful referee for comments that substantially improved the original draft. We would also like to thank Benjamin Bricker and Brian Bucks for comments on an earlier draft of the article. All errors are our own.

Received May 2010; accepted April 2012.

${ }^{1}$ Kennan and Wilson (1989, p. S88) make note in their review of the literature that "a major component of the data is the duration of strikes [and] that most strikes involve sophisticated and seasoned participants." 
school student athletes when committing to attend a university on a football scholarship. ${ }^{2}$ Universities covet highly skilled football players because a successful college football team can earn a university millions of dollars annually; in fact, Brown (1993) estimates a premium college football player generates over $\$ 500,000$ in annual revenue. ${ }^{3}$

We model a student athlete's decision to accept a scholarship based on a signaling model where players have private information about their ability. The model demonstrates that highability athletes are able to signal private information by delaying commitment to a university scholarship. The model implies that players who delay initial commitment to a university will be higher ability ex post than players who commit early.

We test the signaling hypothesis using data on high school athletes from Rivals.com, a web site that follows high school football recruiting. ${ }^{4}$ Our results indicate that, for a given observed ability level, student athletes committing early garner less playing time in subsequent seasons than those who delay initial commitment. For example, using our estimates from the 2004 season, athletes who commit at a typical average early signing date play in 0.21 fewer games, which represents roughly $4 \%$ of the average number of games played (5.90) by our sample in 2004.

The remainder of the article is organized as follows. In section 2 we discuss the recruiting process and details of high school athlete commitment decisions. In section 3 we demonstrate a simple separating equilibrium model of a high school athlete's commitment decision. Section 4 describes our data, estimating equations, and results. Section 5 concludes.

\section{The Recruiting Process}

College coaches spend a significant amount of time recruiting high school athletes. The success of a coach on the field often comes through the quality of the players that he is able to bring to a university. Kahn (2006) indicates that a coach's salary depends on his ability as a recruiter. Coaches identify talent through watching film of thousands of recruits playing high school football, or by watching the student's high school team play in person. Once a coach identifies a talented player, they will try to develop a relationship with the player in order to entice them to accept a scholarship offer. The coach will make frequent phone calls and will travel to talk to the family, friends, and coaches of the recruit.

The National Collegiate Athletic Association (NCAA) regulates the recruiting process of high school football players. Each year in early February, on National Signing Day (NSD), universities may sign up to 25 football players to an athletic scholarship (teams may have 85 scholarship athletes total). ${ }^{5}$ On NSD, student athletes sign binding National Letters of Intent (NLI) stating their commitment to attend a school and play football.

\footnotetext{
${ }^{2}$ High school football players often get advice from their parents or high school coach who may have prior experience with former players making the same decision; however, the decision to commit to a scholarship is their own.

${ }^{3}$ The by-laws governing collegiate athletics prohibit universities from offering a wage to student athletes; the National Collegiate Athletic Association (NCAA) sets these by-laws. Kahn (2006) provides a general overview of the NCAA regulations in several other collegiate sports and examines the cartel-like characteristics of the NCAA. McKenzie and Sullivan (1987) argue that the NCAA is not a cartel.

${ }^{4}$ Over the last decade, the college commitment decisions of high school football players have become increasingly scrutinized and heavily followed. ESPN, a major sports broadcast network, regularly reports on the commitment decisions of most highly regarded high school athletes.

${ }^{5}$ If schools continually sign their limit of players annually, the total scholarship limit means schools must have attrition $(25 \times 4>85)$. Attrition is usually due to poor classroom performance or leaving school early to play professionally, though schools are able rescind a scholarship. According to NCAA legislation and governance circulated in 2009, the NLI only guarantees an athletic scholarship for one year; however, it is common practice to renew annually after the first year.
} 
Recruiting for an entering freshman class begins early the previous year. Contact between a college coach and a high school student athlete is regulated and kept to a minimum for much of the process. ${ }^{6}$ As a result, there is ample room for information asymmetries. Prior to NSD, contact with recruits is limited to one phone call per week outside of scheduled campus and inhome visits, which can take place only during a certain period. Football coaches may view a recruit's high school practice and games only during limited time windows.

The size of the athletics budget and the quality of the football program determine the number of recruits that a university will target. Large universities spend at least $\$ 100,000$ and sometimes as much as $\$ 1,000,000$ annually on recruiting of high school football players. For example, the University of Tennessee reported that it spent $\$ 900,000$ on football recruiting in 2007, while the University of Mississippi spent nearly $\$ 400,000$. For comparison, of the 12 teams in their athletic conference, the University of Mississippi budget ranked ninth (Feldman 2007).

In the absence of pay, a scholarship varies only by the quality of the education and quality of the football program. The quality of the coaching staff and the quality of the facilities will allow the athlete to become a better player; the exposure at a university will allow the athlete to showcase his skill to the public and to future employers in professional football leagues. Kahn (2006, p. 13) points out that "it is likely that NCAA rules on player compensation raise the [marginal revenue product] of effective coaches and the value of top quality facilities, since these become the primary means of attracting athletes."

The maximum number of commitments per year is 25 , but a school may offer scholarships to more than 100 players during a recruiting period. Schools offer many scholarships understanding that the probability of signing any one player is low. This also means that a player knows that if he waits too long and 25 players have already committed, the scholarship offer may no longer be available. The scholarship offer is revocable, and, once offered, the school may lose interest in the player. ${ }^{7}$

Although the offer is not contractually binding on either side until a recruit signs his NLI on NSD, many recruits announce their decisions early through a verbal commitment. It is relatively uncommon for recruits to change their college decision between announcing a verbal commitment and signing the formal contract, although it does happen. ${ }^{8}$ Typically, if a recruit changes his commitment decision it is because of coaching turnover at the university or a better opportunity arising. For the most part, recruiting stops once a player has signed his letter of intent. The penalty for transferring to another school after signing a NLI is for the player to sit out a season before playing for another school. ${ }^{9}$

\footnotetext{
${ }^{6}$ New forms of communication cause these rules to be in a constant state of flux. For example, because the NCAA did not explicitly prohibit sending text messages, some coaches sent multiple text messages per day to recruits (Feldman 2007). The NCAA later explicitly prohibited text messaging (O'Neil 2008). Yen (2011) also provides further details on the NCAA recruiting process.

${ }^{7}$ Scholarships may remain open after NSD for the most talented players. Two recent examples are Terrell Pryor (class of 2008) and David Oku (class of 2009). Three schools (Ohio State University, Pennsylvania State University, and the University of Michigan) kept a scholarship open for Terrell Prior until after NSD. Two schools (Syracuse University and the University of Tennessee) kept a scholarship open for David Oku until after NSD. Crabtree (2009) and Staples (2008) describe these stories.

${ }^{8}$ Staples (2012) finds that $12.4 \%$ of top football recruits made such a change in commitment.

${ }^{9}$ A player in our sample can transfer without sitting out a season if he transfers to a Football Championship Subdivision (FCS, formerly I-AA), Division II, or Division III school. The exposure at these schools is much lower than at a top FBS school.
} 


\section{Modeling the Commitment Decision}

This section presents a simple model examining the decision of a student-athlete to accept a scholarship offer to attend a particular university. The model assumes the student-athlete holds private information on their ability and reveals this information through the decision when to commit to accept a particular scholarship offer. The model derives a single crossing property that allows a separating equilibrium where a student-athlete with better private information makes a later commitment. Potential college student athletes may be especially likely to hold private information about their abilities considering the stringent rules the NCAA imposes on contact with coaches and the imperfect ability of coaches to judge young athletes. For an econometric model of the factors that recruits consider in the decision on what scholarship to accept, see Dumond, Lynch, and Platania (2008).

Let $i$ index the type of private information that the student-athlete holds. An increase in $i$ is associated with a student-athlete holding more "positive" private information, which will make him a higher quality student-athlete. There are two time periods: the current time $(T=0)$ and a future time $(T=t)$. At the current time, the student-athlete may commit to his most preferred scholarship offer and derive an expected utility $S$. Alternatively, the student-athlete can delay the commitment decision until time $t$. We assume that by time $t$, student-athlete $i$ receives a more preferable scholarship offer with probability $p_{i}$, and $p_{i}$ increases with $i$. The expected utility from the more preferred offer is $U_{p}$, where $U_{p}>S$. The cost of delaying commitment is $C$ for student athletes with all types of private information. ${ }^{10}$

The private information type that is just indifferent between committing now and delaying commitment is type $\hat{\imath}$, so that $C=p_{\hat{\imath}}\left(U_{p}-S\right)$. Because the expected benefit from delaying commitment, $p_{i}\left(U_{p}-S\right)$, increases with $i$ and the cost of delaying commitment does not vary with $i$, those with lower quality (private information) commit now $\forall i<\hat{l}$ ), and those with higher quality (private information) commit later $(\forall i>\hat{i})$. The resulting separating equilibrium is based on the quality of private information held by the student-athlete and the fact that this information increases the probability a more preferred scholarship is offered.

\section{Empirical Tests}

We test for evidence of signaling using ex-post data on collegiate playing careers matched to data on the timing of the original commitment student athletes make to accept a football scholarship. Our prediction is that high-ability types will delay initial commitment, or that committing to a football scholarship early is associated with lower ability ex post.

Our measure of ex post quality is the number of games an athlete plays in a football season. The primary reason for this choice is to have a uniform measure across position types. Some positions have measurable outcomes (e.g., for running backs, a measure of quality is number of times they touch the ball and number of yards they run for) whereas others do not (an offensive lineman has no specific quality measure). For all positions, playing in a game

${ }^{10}$ These costs are associated with the student-athlete not resolving the uncertainty in their decision resulting in stress. Modeling this cost as the probability a scholarship is withdrawn results in a separating equilibrium with similar empirical implications. 
demonstrates higher quality than not playing. The data on the number of games student athletes play in come from College Football Stats.com (CFBstats.com).

We measure the timing of commitment as the number of days prior to the NSD that a recruit commits to a university. We collect information on the commitment date of recruits from Rivals.com. ${ }^{11}$ Figure 1 shows the distribution of scholarship commitments relative to the NSD. As shown in Figure 1, many recruits (about 10\% of our sample) wait until NSD to commit. ${ }^{12}$ Rivals.com gathers information on the physical characteristics of student athletes, such as height, weight, and speed, and it ranks recruits according to a subjective measure of observed ability.

The Rivals.com recruiting data start in 2002 with that year's freshman class and spans through the 2005 freshman class, for a total of four years. The game statistics data starts with the 2003 season, when the initial recruiting class is sophomores, and spans through the 2006 season, one year after most of the initial class graduates. Table 1 shows how the recruiting class data correspond to the game statistics data. Our sample is limited to 66 major Football Bowl Subdivision colleges from the Bowl Championship Series (BCS) conferences: the Atlantic Coast, the Big 10, the Big 12, the Big East, the Southeastern, and the Pacific 10, as well as one unaffiliated university (Notre Dame). ${ }^{13}$

Table 2 shows the general trend that players who delay commitment play in more of their team's games in a given season. The second column under each season (2003-2006) shows the average number of days prior to the NLI deadline that a recruit gave his commitment to the school. In general, Table 2 shows that the fewer days prior to the deadline that a recruit gives a commitment, the more games he plays in for any given season. This is especially apparent for athletes who play in most of their teams' games. The average number of days prior to the deadline for athletes who play in 10 or more games is less than the sample average in all years of our data. The average number of days prior to the deadline for athletes who play in three or fewer games is more than the sample average (2005 being the exception).

\section{Ordinary Least Squares (OLS) Estimation}

To formally analyze the link between commitment date and quality, we estimate the number of games played as a linear function of the number of days prior to the deadline, controlling for other factors, using ordinary least squares (OLS): ${ }^{14}$ Our estimating equation is the following:

$$
\begin{aligned}
\text { Games }_{j}= & \alpha+\beta_{1}(\text { Days Pr ior })_{j}+\beta_{2}(\text { Ranked }=1)_{j}+ \\
& \beta_{3}(\text { Ranked }=1 \times \text { Observed Ability })_{j}+\beta_{4}(\text { Home State })_{j}+\eta_{c}+\theta_{p}+\lambda_{l}+\varepsilon_{j} .
\end{aligned}
$$

The dependent variable is the number of games played in a given season for an individual player ( $j$ ), from recruiting class $(c)$, playing position $(p)$, at school $(l)$. Days Prior is the primary

${ }^{11}$ Yahoo! acquired Rivals.com in 2007 for $\$ 100$ million dollars, a testament to the heavy web traffic on the site.

${ }^{12}$ A commitment on the part of a recruit is changeable until NSD. We observe the day that a particular recruit declared . his intention to play for the school with which he eventually signed a NLI.

${ }^{13}$ See Appendix 1 for a list of schools in our sample. Our sample includes Notre Dame, despite not being affiliated with a $\mathrm{BCS}$ conference, because they receive special consideration for BCS bowl games.

${ }^{14}$ When using OLS to estimate $\beta$, we maintain assumptions that $\varepsilon$ is a mean zero random variable that is orthogonal to the covariates in the regression model. A further assumption of the OLS model is that $\varepsilon$ is homoskedastic. In practice, by clustering our standard errors at the school-by-recruiting class level we do not maintain this assumption. 


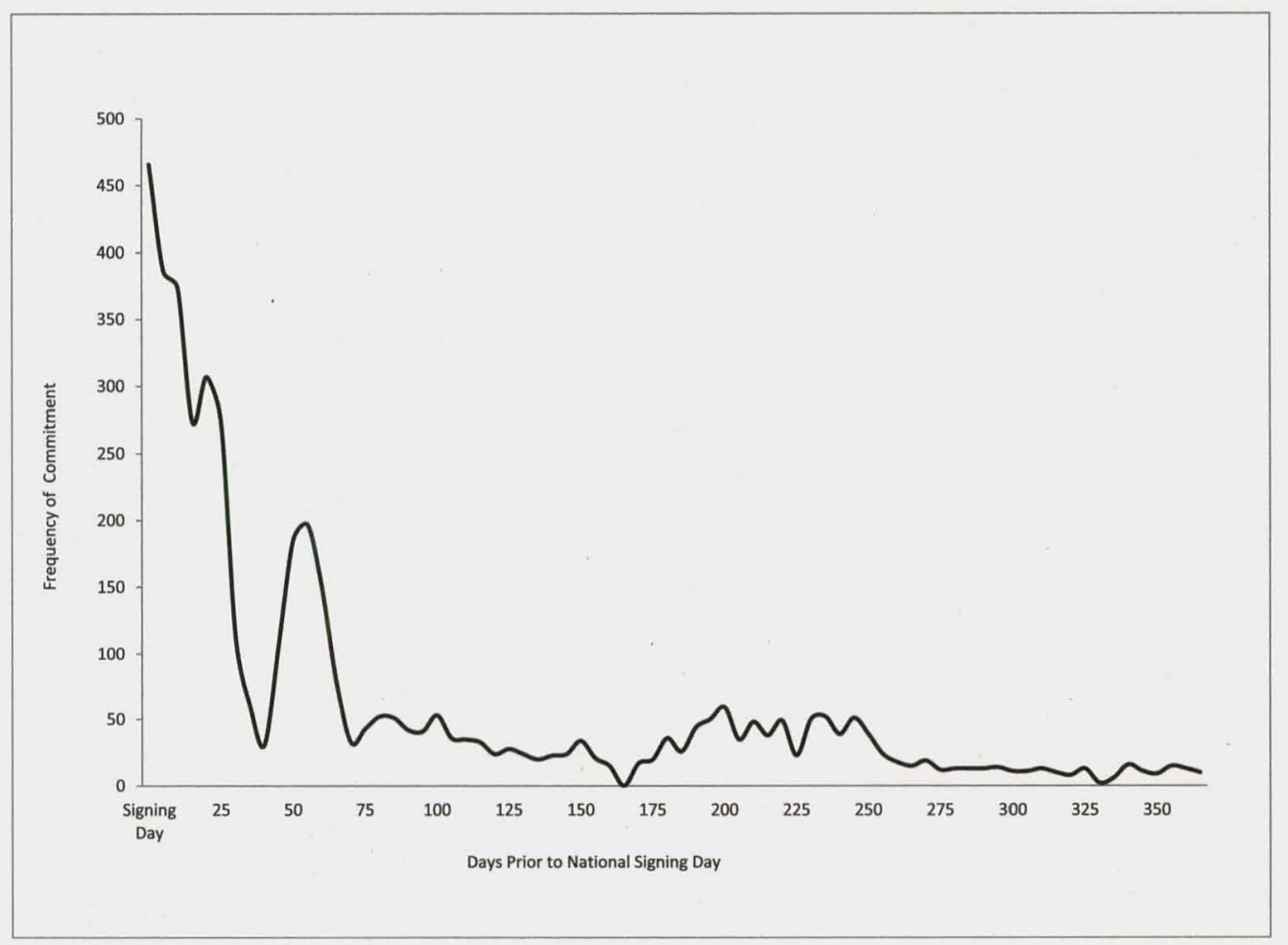

Figure 1. Distribution of Recruit Commitment Days Prior to Signing Day

variable of interest and is the number of days prior to NSD a recruit makes a verbal commitment to play for the school where they sign a scholarship offer. We estimate separate regressions for each season we have games played data on.

Ranked is a variable equal to one if Rivals.com ranks the student athlete by observed ability. Observed Ability is the national ranking of the player from Rivals.com (ranging from 1 to 182 , with 1 being the best ranking). Rivals.com ranks approximately $62 \%$ of high school student athletes in the sample. We use the subjective rank, instead of more objective measures of ability such as speed and strength, because different positions require unique abilities. For example, running speed is important for running backs but less so for defensive linemen, and the fastest defensive lineman is slower than the slowest running back.

Table 1. Data Summary for Recruiting Classes and Game Statistics

\begin{tabular}{lcccc}
\hline & \multicolumn{3}{c}{ Game Statistics (Year) } \\
\cline { 2 - 5 } Recruiting Class & 2003 & 2004 & 2005 & 2006 \\
\hline 2002 & $\mathrm{X}$ & $\mathrm{X}$ & $\mathrm{X}$ & $\mathrm{X}$ \\
2003 & $\mathrm{X}$ & $\mathrm{X}$ & $\mathrm{X}$ & $\mathrm{X}$ \\
2004 & & $\mathrm{X}$ & $\mathrm{X}$ & $\mathrm{X}$ \\
2005 & & $\mathrm{X}$ & $\mathrm{X}$ \\
\hline
\end{tabular}

2006 game statistics include some players from the 2002 recruiting class; however, many of these players were already graduated or were no longer in college for other reasons. Players are eligible to play football for four seasons. Players are not required to play four consecutive years and may take a year to mature physically or recover from injury. It is common practice for players to do this during their freshman season. 
Table 2. Average Number of Days Signed Prior to National Signing Day, by Games Played

\begin{tabular}{|c|c|c|c|c|c|c|c|c|}
\hline \multirow[b]{2}{*}{ Games Played } & \multicolumn{2}{|c|}{2003 Season } & \multicolumn{2}{|c|}{2004 Season } & \multicolumn{2}{|c|}{2005 Season } & \multicolumn{2}{|c|}{2006 Season } \\
\hline & $N$ & Avg. Days & $N$ & Avg. Days & $N$ & Avg. Days & $N$ & Avg. Days \\
\hline 0 & 194 & 64 & 643 & 77 & 617 & 99 & 258 & 95 \\
\hline 1 & 196 & 73 & 156 & 93 & 168 & 78 & 133 & 97 \\
\hline 2 & 134 & 68 & 89 & 76 & 105 & 82 & 89 & 103 \\
\hline 3 & 48 & 94 & 84 & 77 & 103 & 73 & 83 & 99 \\
\hline 4 & 36 & 47 & 63 & 99 & 68 & 108 & 71 & 82 \\
\hline 5 & 37 & 60 & 83 & 85 & 84 & 66 & 75 & 79 \\
\hline 6 & 52 & 58 & 69 & 68 & 85 & 85 & 68 & 84 \\
\hline 7 & 55 & 66 & 69 & 78 & 119 & 81 & 101 & 72 \\
\hline 8 & 77 & 55 & 103 & 75 & 129 & 75 & 110 & 90 \\
\hline 9 & 74 & 50 & 112 & 64 & 187 & 74 & 115 & 97 \\
\hline 10 & 63 & 42 & 167 & 57 & 250 & 80 & 149 & 85 \\
\hline 11 & 92 & 48 & 358 & 56 & 619 & 70 & 240 & 82 \\
\hline 12 & 152 & 50 & 289 & 60 & 460 & 66 & 654 & 81 \\
\hline 13 & 135 & 42 & 68 & 59 & 107 & 80 & 688 & 83 \\
\hline 14 & 10 & 54 & - & - & - & - & 153 & 69 \\
\hline 15 & 4 & 27 & - & - & - & - & - & - \\
\hline Total & 1359 & 59 & 2353 & 71 & 3101 & 79 & 2987 & 85 \\
\hline
\end{tabular}

Home State is a dummy variable equal to one if the player makes a commitment to a school in his state of residence. The rationale for including this variable is that geographically close schools may be able to gain access to information about a recruit that other schools cannot. Finally, $\eta$ measures recruiting class fixed effects, $\theta$ measures position fixed effects, and $\lambda$ is a school fixed effect. We create dummy variables for three types of football positions in our regression analysis: quarterback, "skill" positions (running back, wide receiver, cornerback, safety, linebacker, tight end), and linemen (both offensive line and defensive line). ${ }^{15}$ All specifications cluster standard errors at the school-by-recruiting class level.

Table 3 presents estimation results for Equation 1 both with and without the Ranked and Ranked $\times$ Observed Ability variables. As shown in Panel A of Table 3, the negative relationship between the Days Prior variable and games played is strong in all years, controlling for recruitment class, home state, position, and school. The magnitude of the effect of signaling by delaying commitment on games played is substantial. In 2004 a student who committed 71 days prior to NSD (the mean in 2004) played 0.19 fewer games during the season. The 0.19 games magnitude represents 3\% of the mean number of games played (5.90) in 2004. The Days Prior estimate is precisely estimated, standard errors are small compared to the point estimates, and the estimated effect is statistically significant at no less than the $10 \%$ level in all years.

In Panel B of Table 3, we add the Ranked and Ranked $\times$ Observed Ability variables and reestimate. Adding these variables allows us to isolate unobserved ability by conditioning on known characteristics of the recruit at the time they make a commitment and shows the relative importance of observed and unobserved ability. It also allows us to get an idea of how omitted variable bias may be affecting our results. In Panel A, omitting observed ability biases the coefficient on Days Prior if these two variables are correlated and observed ability is correlated with playing in games.

The primary results from Panel A in Table 3 remain largely unchanged after controlling for observed ability in Panel B. Controlling for observed ability, the signaling mechanism (Days

${ }^{15}$ We drop student athletes recruited as punters and kickers from the sample. 
Prior) is as economically and statistically significant as in Panel A. Using the 2004 estimates, a student who commits 71 days prior to NSD plays in 0.21 fewer games during the season, or roughly $4 \%$ fewer games relative to the mean of 5.90 games played (see Appendix 2).

The measure of observed ability (national ranking) predicts that highly ranked student athletes (ranked closer to 1 than 182) play in more games. In 2004 a top-ranked athlete is expected to play in roughly two more games relative to an unranked athlete. An athlete at the mean national ranking plays in 1.15 more games than an unranked athlete, or roughly $20 \%$ of the average of 5.90 games played. The magnitude of unobserved ability on games played $\left(\hat{\beta}_{1} \times \overline{\text { Days Prior }} / \overline{\text { Games }}\right)$ is roughly $18 \%$ of the magnitude of observed ability on games played $\left(\left\{\hat{\beta}_{2}(\right.\right.$ Ranked $=1)+\hat{\beta}_{3}($ Ranked $\left.=1 \times \overline{\text { Observed Ability })}\} / \overline{\text { Games }}\right)$ at their respective means. Comparisons using 2003, 2005, and 2006 data and estimates yield similar conclusions (see Appendix 2).

The ranking and observed ability effect is larger than the signaling effect; however, we still find considerable information in the Days Prior (signaling) variable. Finding a strong effect for unobserved ability after controlling for observed ability reinforces the usefulness of thinking about the commitment decision as a market where signaling occurs. By delaying commitment, recruits are able to signal a factor that colleges cannot observe, and this factor is important enough to explain ex post quality. Assuming that the observed ability variable sufficiently controls for football skill, this factor represents private information about the student athlete that matters for playing in games. Examples of unobserved ability could include work ethic, ability to grasp more complex playing schemes, effort to stay academically eligible, and ability to prevent injury.

\section{Alternative Estimation}

The nature of our dependent variable, games played, deserves further consideration. Games played is both bottom censored (at zero) and top censored (at the maximum number of games played by a team). It is also a count variable, rather than a continuous variable. An OLS regression may not be appropriate for either of these reasons, so we supplement our OLS estimates with count and censored regression models.

The negative binomial model (a nonlinear count data model) provides consistent and efficient parameter estimates when the dependent variable $(y)$ is a count and $E[y \mid x]<V[y \mid x]$. The negative binomial model assumes that the observed dependent variable is generated by a process that mixes the Poisson and gamma distributions. The conditional density of $Y$ is thus

$$
f\left(y_{j} \mid \mu, \alpha\right)=\frac{\Gamma\left(y_{j}+\alpha^{-1}\right)}{\Gamma\left(y_{j}+1\right) \Gamma\left(\alpha^{-1}\right)}\left(\frac{\alpha^{-1}}{\mu_{j}+\alpha^{-1}}\right)^{\alpha^{-1}}\left(\frac{\mu_{j}}{\mu_{j}+\alpha^{-1}}\right)^{y} \text { for } \alpha>0, y_{j} \in\{0,1,2, \ldots\}
$$

with mean parameter $\mu_{j}=E\left[y_{j} \mid x_{j}\right]=e^{x_{j}^{\prime} \beta}$ to be estimated. Here $\Gamma(\cdot)$ is the gamma distribution and $\alpha$ is the dispersion parameter. ${ }^{16}$ The log likelihood function is maximized and solved to find $\hat{\beta}^{N B}$.

If the dependent variable (games played) is a proxy for the latent and true but unobserved variable (games played*) (where games played* can be less than zero and greater than the maximum number of games), then a censored regression model is appropriate. The observed games played variable cannot differentiate between a player who should truly have zero games

${ }^{16}$ If $\alpha$ is zero, then the model collapses to a Poisson distribution; if $\alpha$ is positive, then the data are overdispersed $(E[y \mid x]<V[y \mid x])$ and an alternative to the Poisson is appropriate. Our estimates of $\alpha$ in Table 4, Panel B, are positive. 
Table 3. Test of Early Commitment on Games Played (OLS)

\begin{tabular}{|c|c|c|c|c|}
\hline & (1) & (2) & (3) & (4) \\
\hline & 2003 & 2004 & 2005 & 2006 \\
\hline \multicolumn{5}{|c|}{ Panel A. Does not include national ranking } \\
\hline $\begin{array}{l}\text { Days prior to } \\
\text { National } \\
\text { Signing Day }\end{array}$ & $\begin{array}{r}-0.0023^{*} \\
(0.0014)\end{array}$ & $\begin{array}{c}-0.0026^{* *} \\
(0.0011)\end{array}$ & $\begin{array}{r}-0.0017^{*} \\
(0.0009)\end{array}$ & $\begin{array}{c}-0.0020^{*} \\
(0.0010)\end{array}$ \\
\hline $\begin{array}{l}\text { Observations } \\
R^{2}\end{array}$ & $\begin{array}{r}1317 \\
0.33\end{array}$ & $\begin{array}{r}2273 \\
0.29\end{array}$ & $\begin{array}{r}3002 \\
0.26\end{array}$ & $\begin{array}{r}2893 \\
0.11\end{array}$ \\
\hline \multicolumn{5}{|c|}{ Panel B. Includes national ranking } \\
\hline $\begin{array}{l}\text { Days prior to } \\
\text { National } \\
\text { Signing Day }\end{array}$ & $\begin{array}{r}-0.0024^{*} \\
(0.0014)\end{array}$ & $\begin{array}{c}-0.0029 * * \\
(0.0011)\end{array}$ & $\begin{array}{c}-0.0020^{* *} \\
(0.0009)\end{array}$ & $\begin{array}{c}-0.0023 * * \\
(0.0010)\end{array}$ \\
\hline Ranked $=1$ & $\begin{array}{l}2.021^{* *} \\
(0.414)\end{array}$ & $\begin{array}{l}2.096 * * \\
(0.278)\end{array}$ & $\begin{array}{l}1.395^{* *} \\
(0.242)\end{array}$ & $\begin{array}{l}1.208^{* *} \\
(0.281)\end{array}$ \\
\hline $\begin{array}{l}\text { Ranked }=1 \times \\
\text { Observed } \\
\text { Ability }\end{array}$ & $\begin{array}{c}-0.023^{* *} \\
(0.006)\end{array}$ & $\begin{array}{c}-0.019 * * \\
(0.003)\end{array}$ & $\begin{array}{c}-0.011^{* *} \\
(0.003)\end{array}$ & $\begin{array}{c}-0.010^{* *} \\
(0.003)\end{array}$ \\
\hline Observations & 1317 & 2273 & 3002 & 2893 \\
\hline$R^{2}$ & 0.34 & 0.31 & 0.27 & 0.11 \\
\hline
\end{tabular}

All regression models include dummies for year of recruitment, position played, school, and whether the student attended a home-state school. Standard errors are clustered at school-recruiting class and are reported in parentheses.

* Significant at the $10 \%$ level.

** Significant at the $5 \%$ level.

played and one who should have negative games played. In this case, games played is censored at the tails and OLS may not be appropriate. Thus, we also estimate a double censored model based on Equation 1 to account for the censored nature of our dependent variable: ${ }^{17}$

for each athlete $j$ in school $s$ and year $t$ :

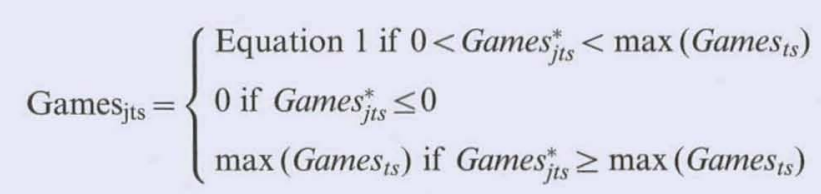

We reestimate Equation 1 using both censored and negative binomial regressions; Panel A of Table 4 presents the censored regressions, and Panel B of Table 4 presents estimates from the negative binomial model. Qualitatively there is little difference between the alternative results and standard OLS.

In the censored regression, the impact of committing one day earlier is playing in 0.0031 to 0.0048 fewer games, which implies that an athlete committing on NSD plays in 0.18 to 0.41 more games than an athlete that commits at the average number of days prior to NSD

\footnotetext{
${ }^{17}$ Because some schools $(s)$ play more games in a year $(t)$ than others, our censoring is school and year specific and may vary across observations. We use the cnreg (censored normal regression) command in Stata (which is qualitatively similar to the Tobit model but allows the upper limit censor value to vary across observations) in our estimates. Thus, errors are assumed to be normally distributed and estimates are derived via maximum likelihood estimation. In the censored model, the number of games played $\left(\right.$ Games $\left._{j}\right)$ is observed, but the latent variable (Games $\left.{ }_{j}^{*}\right)$ is unobserved. Players can show their quality (lack of quality) by playing in more (fewer) games. However, in reality a player can play in no less than zero games and no more than 15 games.
} 
Table 4. Test of Early Commitment on Games Played (Censored and Count Models)

\begin{tabular}{|c|c|c|c|c|}
\hline & 2003 & 2004 & 2005 & 2006 \\
\hline \multicolumn{5}{|c|}{ Panel A. Double censored } \\
\hline $\begin{array}{l}\text { Days prior to } \\
\text { National } \\
\text { Signing Day }\end{array}$ & $\begin{array}{c}-0.0031 * \\
(0.0019)\end{array}$ & $\begin{array}{c}-0.0043^{* *} \\
(0.0021)\end{array}$ & $\begin{array}{c}-0.0048^{* *} \\
(0.0017)\end{array}$ & $\begin{array}{c}-0.0048^{* *} \\
(0.0018)\end{array}$ \\
\hline Ranked $=1$ & $\begin{array}{l}2.795 * * \\
(0.591)\end{array}$ & $\begin{array}{l}4.357 * * \\
(0.547)\end{array}$ & $\begin{array}{l}2.311 * * \\
(0.458)\end{array}$ & $\begin{array}{l}2.192^{* *} \\
(0.517)\end{array}$ \\
\hline $\begin{array}{l}\text { Ranked }=1 \times \\
\text { Observed } \\
\text { Ability }\end{array}$ & $\begin{array}{c}-0.031^{* *} \\
(0.008)\end{array}$ & $\begin{array}{c}-0.042 * * \\
(0.006)\end{array}$ & $\begin{array}{c}-0.017 * * \\
(0.006)\end{array}$ & $\begin{array}{c}-0.018 * * \\
(0.006)\end{array}$ \\
\hline $\begin{array}{l}\text { Observations } \\
\text { Pseudo- } R^{2}\end{array}$ & $\begin{array}{r}1317 \\
0.08\end{array}$ & $\begin{array}{r}2273 \\
0.08\end{array}$ & $\begin{array}{r}3002 \\
0.07\end{array}$ & $\begin{array}{r}2893 \\
0.03\end{array}$ \\
\hline \multicolumn{5}{|c|}{ Panel B. Negative binomial } \\
\hline $\begin{array}{l}\text { Days prior to } \\
\text { National } \\
\text { Signing Day }\end{array}$ & $\begin{array}{c}-0.00055 \\
(0.00036) \\
{[-0.0034]}\end{array}$ & $\begin{array}{c}-0.00040 \\
(0.00027) \\
{[-0.0024]}\end{array}$ & $\begin{array}{c}-0.00035^{*} \\
(0.00018) \\
{[-0.0024]}\end{array}$ & $\begin{array}{c}-0.00027 * * \\
(0.00012) \\
{[-0.0025]}\end{array}$ \\
\hline Ranked $=1$ & $\begin{array}{l}0.3414^{* *} \\
(0.0763) \\
{[2.075]}\end{array}$ & $\begin{array}{l}0.4565^{* *} \\
(0.0621) \\
{[2.692]}\end{array}$ & $\begin{array}{l}0.2685^{* *} \\
(0.0438) \\
{[1.862]}\end{array}$ & $\begin{array}{l}0.1472^{* *} \\
(0.0305) \\
{[1.339]}\end{array}$ \\
\hline $\begin{array}{l}\text { Ranked }=1 \times \\
\text { Observed } \\
\text { Ability }\end{array}$ & $\begin{array}{c}-0.0038^{* *} \\
(0.0011) \\
-0.0232]\end{array}$ & $\begin{array}{c}-0.0043^{* *} \\
(0.0008) \\
{[-0.0251]}\end{array}$ & $\begin{array}{c}-0.0021^{* *} \\
(0.0005) \\
-0.0147]\end{array}$ & $\begin{array}{c}-0.0011^{* *} \\
(0.0004) \\
{[-0.0100]}\end{array}$ \\
\hline Observations & 1317 & 2273 & 3002 & 2893 \\
\hline Pseudo- $R^{2}$ & 0.05 & 0.04 & 0.03 & 0.01 \\
\hline
\end{tabular}

All regression models include dummies for year of recruitment, position played, school, and whether the student attended a home-state school. Standard errors are clustered at school-recruiting class and are reported in parentheses. In Panel $\mathrm{B}$, the average response across athletes is reported in brackets.

* Significant at the $10 \%$ level.

** Significant at the $5 \%$ level.

(Appendix 2). As in the OLS results, the magnitude of unobserved ability on games played is between $13 \%$ and $30 \%$ of the magnitude of observed ability.

The regression coefficients from the negative binomial model are presented in Panel B of Table 4. Unlike the linear model, the coefficients themselves do not reveal the impact of a oneunit change in the covariates on games played; rather, these estimates need to be scaled by $\exp \left(x_{j}^{\prime} \hat{\beta}^{N B}\right)$, and the marginal impact varies across individuals $(j)$. The "average response" across individuals is a general and concise estimate of this marginal impact, and it is summarized by $\hat{\beta}_{k}^{N B} \bar{y}$ for variable $k$ in the $\hat{\beta}^{N B}$ matrix (Cameron and Trivedi 2001). The average response is presented in squared brackets in addition to coefficient estimates in Panel B of Table 4.

The negative binomial model predicts that an athlete committing on NSD will play between 0.17 and 0.21 more games than an athlete committing at the average number of days before NSD, a result that is similar to the OLS estimates (see Appendix 2). The negative binomial model also predicts that the average ranked player will play in roughly one fewer game than a top ranked athlete.

A final concern with using the number of games a student-athlete played in as the dependent variable is that it may be a noisy measure of quality. There are many reasons a student-athlete may play in a game, for example, injury, poor performance of teammates, or substituting for starting players when the outcome is no longer in question. With this in mind we estimate Equation 1 using other measures of quality. As an alternative, we measure quality 
by how many points a player scores and how many yards they gain in a game. These results also show delayed commitment to be a sign of quality: Players who sign earlier score fewer touchdowns and have fewer yards. These results (available from the authors upon request) include only subsamples of offensive skilled players, so the number of observations is much smaller, which unfortunately makes them quite statistically imprecise.

\section{Conclusion}

The regulations on contact between a college coach and a high school student athlete allows for information asymmetries during the recruiting process. In the context of our model, our empirical results support the idea that student athletes are able to signal private information about their ability by delaying commitment to a university. We find athletes who commit to a university earlier garner less playing time in subsequent seasons than those who delay initial commitment. At a typical average early signing date, early committing athletes play in 0.21 fewer games. The magnitude is close to $20 \%$ of the size of the estimated impact of observed ability, measured at the mean. Our results demonstrate that signaling exists in an instance where the economic agent is arguably less sophisticated than previous studies and for a transaction prohibiting monetary exchange for services.

Appendix 1. Colleges in Our Sample

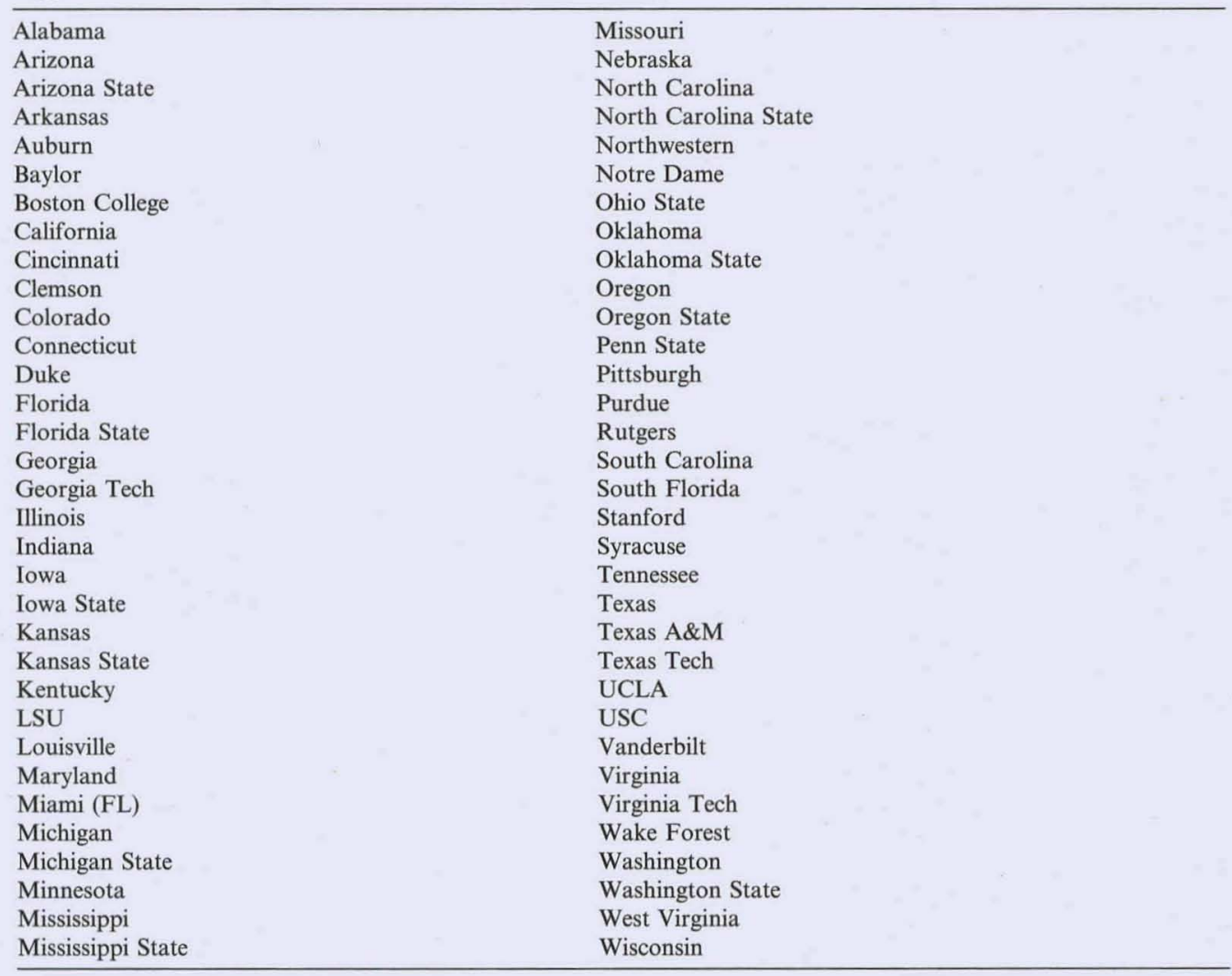


Appendix 2. Magnitudes of Estimated Coefficients

\begin{tabular}{|c|c|c|c|c|}
\hline & (1) & (2) & (3) & (4) \\
\hline & 2003 & 2004 & 2005 & 2006 \\
\hline \multicolumn{5}{|l|}{ Panel A. Means } \\
\hline Games played & 6.08 & 5.90 & 6.94 & 9.10 \\
\hline Days prior to NSD & 58.49 & 70.93 & 79.72 & 85.43 \\
\hline Ranking $\mid$ Ranked $=1$ & 46.31 & 49.60 & 47.78 & 48.21 \\
\hline \multicolumn{5}{|l|}{ Panel B: OLS regression } \\
\hline \multicolumn{5}{|c|}{ Marginal effect evaluated at mean of: } \\
\hline Days prior to NSD & -0.14 & -0.21 & -0.16 & -0.20 \\
\hline Ranking $\mid$ Ranked $=1$ & 0.97 & 1.15 & 0.85 & 0.75 \\
\hline \multicolumn{5}{|c|}{ And as a percentage of mean games played } \\
\hline Mean days prior to NSD & 2 & 4 & 2 & 2 \\
\hline Mean ranking & 16 & 20 & 12 & 8 \\
\hline \multicolumn{5}{|l|}{ Panel C: Censored regression } \\
\hline \multicolumn{5}{|c|}{ Marginal effect evaluated at mean of } \\
\hline Days prior to NSD & -0.18 & -0.30 & -0.38 & -0.41 \\
\hline Ranking $\mid$ Ranked $=1$ & 1.34 & 2.29 & 1.49 & 1.32 \\
\hline \multicolumn{5}{|c|}{ And as a percentage of mean games played } \\
\hline Mean days prior to NSD & 3 & 5 & 6 & 4 \\
\hline Mean ranking & 22 & 39 & 21 & 14 \\
\hline \multicolumn{5}{|c|}{ Panel D: Negative binomial regression } \\
\hline \multicolumn{5}{|c|}{ Average response evaluated at mean of } \\
\hline Days prior to NSD & -0.20 & -0.17 & -0.19 & -0.21 \\
\hline Ranking $\mid$ Ranked $=1$ & 1.00 & 1.45 & 1.16 & 0.86 \\
\hline \multicolumn{5}{|c|}{ And as a percentage of mean games played } \\
\hline Mean days prior to NSD & 3 & 3 & 3 & 2 \\
\hline Mean ranking & 16 & 25 & 17 & 9 \\
\hline
\end{tabular}

Coefficient estimates from each regression model are evaluated at the mean. For the ranking, the evaluation is

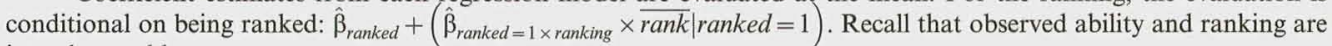
interchangeable.

\section{References}

Brown, Robert. 1993. An estimate of the rent generated by a premium college football player. Economic Inquiry 31:671-84.

Cameron, Adrian, and Pravin Trivedi. 2001. Essentials of count data regression. In A companion to theoretical econometrics, edited by Badi Baltagi. Oxford: Blackwell Press, pp. 331-48.

Conlin, Michael. 1999. Empirical test of a separating equilibrium in national football league contract negotiations. RAND Journal of Economics 30:289-304.

Conlin, Michael, and Patrick Emerson. 2003. Multidimensional separating equilibria and moral hazard: An empirical study of national football league contract negotiations. Review of Economics and Statistics 85:760-5.

Crabtree, Jeremy. 2009. Still undecided on college choice, top back Oku switches high schools. Sports Illustrated. Accessed November 2009. Available at http://sportsillustrated.cnn.com/2009/football/ncaa/02/24/oku/index.html.

Dumond, J. Michael, Allen Lynch, and Jennifer Platania. 2008. An economic model of the college football recruiting process. Journal of Sports Economics 9:67-87.

Feldman, Bruce. 2007. Meat market: Inside the smash-mouth world of college football recruiting. New York: ESPN Press.

Kahn, Lawrence. 2006. The economics of college sports: Cartel behavior vs. amateurism. IZA Discussion Paper No. 2186.

Kennan, John, and Robert Wilson. 1989. Strategic bargaining models and interpretation of strike data. Journal of Applied Econometrics 4S:S87-S130.

McKenzie, Richard, and E. Thomas Sullivan. 1987. Does the NCAA exploit college athletes? An economics and legal reinterpretation. Antitrust Bulletin 32:373-99. 
O'Neil, Dana. 2008. NCAA opts to uphold ban on text messaging recruits. ESPN.com. Accessed November 2009. Available at http://sports.espn.go.com/ncaa/news/story?id=3193796.

Spence, Michael. 1973. Job market signaling. Quarterly Journal of Economics 83:355-79.

Staples, Andy. 2008. Decision on hold: Pryor won't choose school until hoops season ends, Sports Illustrated. Accessed November 2009. Available at http://sportsillustrated.cnn.com/2008/writers/andy_staples/02/19/pryor.update/.

Staples, Andy. 2012. The Commitment Project: Studying recruits, college football edition, Sports Illustrated. Accessed March 2012. Available at http://sportsillustrated.cnn.com/2012/writers/andy_staples/01/20/commitment.project/ index.html.

Tracy, Joseph. 1987. An empirical test of an asymmetric information model of strikes. Journal of Labor Economics 5:149-73.

Yen, Albert. 2011. Early scholarship offers and the NCAA. Boston College Law Review 52:585-616. 